\title{
A GENERAL METHOD FOR THE PREDICTION \\ OF PRECIPITATE COMPOSITIONS
}

\author{
J. S. Slaney
}

Abstract

The shortcomings of present methods of prediction are considered and a new method is proposed. This is based upon the maximum solubility of individual elements in the precipitating phase and the availability of such elements in the alloy. The plan of a computer program is suggested and a comparison made between an analyzed and predicted composition of gamma prime.

J. S. Slaney is Senior Research Associate with Latrobe Stee1 Company, Latrobe, Pennsylvania. 
Introduction. Methods of prediction of the formation of phases such as sigma in superalloys, depend upon assumptions regarding the composition of precipitating phases such as carbides, borides and more importantly, the strenghtening phase. After the elements of these phases are removed, the formula given by Beck and his co-workers (1) is applied to the remaining matrix to obtain an average electron-vacancy number. This number is a measure of the propensity of the matrix to form electron compounds. This type of prediction calculation has come to be known by the name PHACOMP.

Discussion. The anomolous behavior of Incone1 $713 \mathrm{C}$ has been something of a problem when trying to apply the PHACOMP calculations to predict the formation of sigma. Consideration of this problem has led to this proposal for a general method of prediction of precipitating phase composition.

Although a safe number has been developed for some super alloys, it has frequently been found that alloys in the 713 range, while calculating to a low and supposedly-safe number, will in fact form sigma on long-time exposure at temperature. This effect has been well documented in the work being done by Collins and Kortovich at TRW on an Air Force contract (2). In this contract work, the method most successful in dealing with $713 \mathrm{C}$ has been that using the composition of gamma-prime due to Dreshfield which is taken to be

$$
\mathrm{Ni}_{2.95}(\mathrm{Mo}+\mathrm{W}) .05(\mathrm{Ti}+\mathrm{Al}+\mathrm{Ta}+\mathrm{Cb}+\mathrm{Zr}+0.5 \mathrm{~V}+0.3 \mathrm{Cr})
$$

this being the composition of the gamma-prime which he found in the alloy TAZ8B. The figures in front of vanadium and chromium are that proportion of the total atomic percentage of the element present in the alloy. Although calculations, based on the use of this composition for gamma-prime have been more successful than others, in $713 \mathrm{C}$ at any rate, this is not the composition one might expect from Guard and Westbrook's work on the nickel-aluminum system (3). Their phase diagram, Fig. 1, for approximately $2100^{\circ} \mathrm{F}$ shows cobalt and copper substituting almost exclusively on the nickel side of NizAl; titanium, silicon, vanadium and manganese on the aluminum side and about 50/50 partition of iron, chromium and molybdenum between the two sides. Decker and Bieber's work on 713C (4) has indicated that nearly a11 of the columbium goes into the aluminum side while Arbusov (5) shows tungsten on both sides.

The Guard and Westbrook phase diagram for NizAl gives a clue as to the reason for the difficulty with $713 \mathrm{C}$. Their diagram shows that cobalt substitutes on the nickel side almost exclusively. Now, at the time the original calculations concerned with sigma control in Udimet 700 were made (6), there was no chemically-analyzed composition of gamma-prime available other than that given by Decker and Bieber in their work on 713C - which contains no cobalt. Consequently, the assumption was made that the gamma-prime in Udimet 700 also contained no cobalt, whereas there must have been a considerable amount in it since this alloy contained about $18 \%$ of this element. This omission was repeated in other assumed compositions for gamma-prime (7). Now, because 
the number given by Beck and his co-workers was found to be much too high for this control work, the electron-vacancy number for a similar alloy was used as a target figure. This alloy was a Udimet 500 heat known to be sigma free. At this point it should be pointed out that when Beck gave his range of numbers for the formation of sigma he was referring to the single phase region (sigma) whereas of course, we here are concerned with the two-phase (gamma plus sigma) region, which must be associated with a much wider range of electron vacancy numbers.

To return to the present argument, it will be noted that the sigmafree Udimet 500 alloy used for a target figure was also an alloy which contained a lot of cobalt. The consequence was that the same error was repeated in the Udimet 500 target calculation and the Udimet 700 control calculation; thus, the two errors cancelled each other. However, when the calculation was applied to $713 \mathrm{C}$ alloy, we had the built-in error from the Udimet 500 calculation but no error in the $713 \mathrm{C}$ calculation because the composition of the gamma-prime was now more nearly correct, and the error was not cancelled.

Effect of Cobalt in The Sigma Calculation. Since the cobalt substitutes for nickel, it does not improverish the matrix in nickel, but where it is present in an a11oy, it will be removed from the matrix by the precipitation reaction. The consequence of this is that it will actually be less effective in forming sigma although in the old method it will be calculated as being more effective than it is. Notice that this will tend to rate the number relatively higher -- hence more sigma prone -- in a cobalt-containing alloy and relatively lower -- hence safer - - in a lower-cobalt alloy. Thus, it will be seen that $713 \mathrm{C}$ alloy will calculate to a low and safe number when in fact it will likely form sigma; and this is known to be the case.

It should be noted that this effect will only be seen when the alloy matrix is near to the critical gamma-gamma+sigma boundary as is the case with $713 \mathrm{C}$. For instance, there are several cobalt-free alloys in the work being done at TRW which do not form sigma; however, these alloys are so far away from the sigma boundary that they do not form sigma anyway and the error does not show up.

These considerations lead to a type of calculation which should have quite general application. Given below are the outlines of such a calculation.

Assumptions Used in The Calculation. It should be noted that the numbers which are mentioned in this section can be changed if necessary as is shown in the appendix.

\section{Carbides}

1. If molybednum plus tungsten atomic percent is more than 3.5 , then $\mathrm{M}_{6} \mathrm{C}$ is formed to reduce the residual molybdenum plus tungsten to less than 3.5 atom percent. 
2. If columbium and/or tantalum are present at more than .4 atom percent, the carbon forms MC.

3. If less than .4 atom percent of columbium and/or tantalum is present, half the carbon goes to form $M C$ and half goes to $\mathrm{M}_{23} \mathrm{C} 6$. As mentioned above, provision is made for these to vary in a proposed computer program.

Borides

Assume all of the boron forms $\mathrm{M}_{3} \mathrm{~B}_{2}$ of composition $\mathrm{Mo}_{3} \mathrm{~B}_{2}$.

Gamma Prime

Make the obviously-wrong assumption that after the formation of the carbides, all of the aluminum, titanium, columbium and tantalum form gamma prime. As a first approximation, the percentage of substituting elements in the gamma prime will be given by the maximum solubility of the various elements at the temperature of exposure multiplied by the percentage available in the alloy. For example, the chromium in alloy 713 is 14.45 atom percent. Taylor and Floyd (8) report that chromium solubility in gamma prime at $1562^{\circ} \mathrm{F}$ is about 16 atom percent. So we might expect $16 \%$ X $14.45 \%$ which equals 2.32 atom percent in gamma prime. Decker and Bieber in their determinations found 2.25 atom percent. Not a bad correlation. As a matter of fact, the whole of the gamma prime composition for $713 \mathrm{C}$ as calculated by this method (Appendix II) compares quite favorably with that determined by Decker and Bieber.

Of course when we speak of the maximum solid solubility we are really referring to the maximum solubility at the temperature at which the alloy is being soaked for a long period of time. We don't have all of this data now but as a first approximation we can use the data such as that of Guard and Westbrook and of Floyd and Taylor. Multiplying the atomic percent of the element in the alloy by its maximum solubility at the nearest temperature we have available, will give the expected approximate composition of the gamma-prime. Later when more precipitate compositions are determined, we could use the known precipitate composition to correct the maximum solid solubility of the element. This is possible if the atomic percentage in the precipitate and the atomic percent of the alloy are known because the maximum solid solubility in atomic percent is equal to the observed atomic percent in the precipitate divided by the atomic percentage available in the alloy.

Calculations. Appendix I lists the assumptions made for this calculation and suggests a possible plan for a computer program. One of the objects of this program would be to have various constants in it so that these could be changed as more accurate information becarne available. Appendix II is a sample calculation of the variable ganma prime program carried out on $713 \mathrm{C}$ alloy. This serves as a check on the prediction method because we have a calculated composition for the gamma primc in 
this alloy and an observed composition arrived at by chemical means. The comparison is shown at the end of the appendix and is not too bad. Appendix III is a calculation for a typical Udimet 700 analysis with a predicted value for the gamma prime. When this is analyzed in the future, the accuracy of the prediction (and the assumptions) will be checked again.

No changes are proposed for the final calculation of electronvacincy number in this note, but I believe that a more accurate prediction of the precipitating phases will lead us to a better idea of the composition of the matrix from which the sigma forms.

With regard to the final electron-vacancy number, it cannot be emphasized too strongly that this depends upon the assumptions made in the calculation and consequently, so does the "safe" number. Therefore every time an $\mathrm{N}_{\mathrm{V}}$ number is quoted, the assumptions made or method used to obtain this number should be referenced.

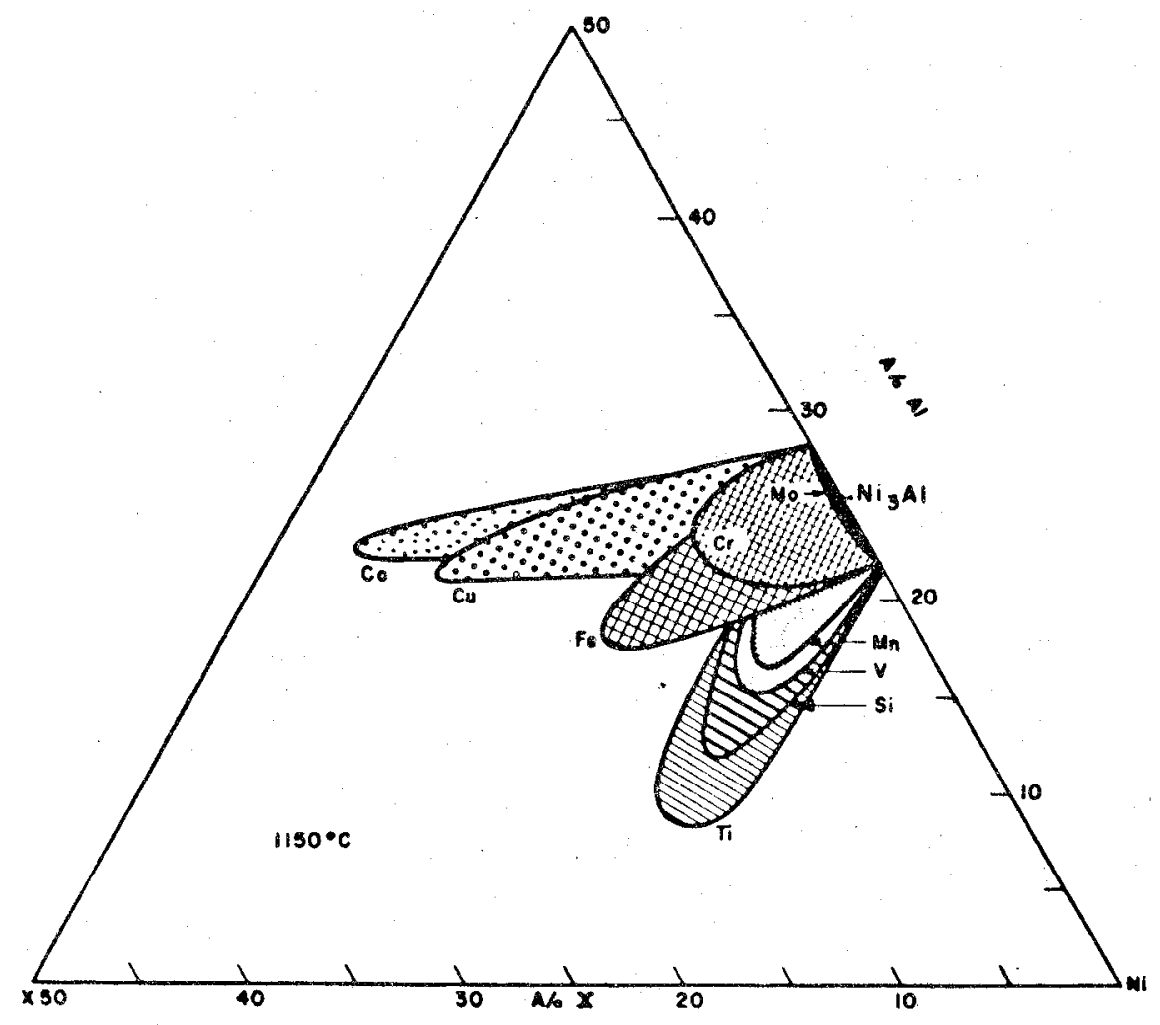

Fig. 1 - NizAl solid - solution field at approximately $2100^{\circ} \mathrm{F}$ for various ternary alloys. After Guard and Westbrook (3). 


\section{REFERENCES}

(1) Sheldon Rideout, W. D. Manly, E. L. Kaman, B.S. Lement and Paul A. Beck: Intermediate Phases in Ternary Alloy Systems of Transition Elements, pp. 872-876, Journal of Metals, October, 1951.

(2) H. E. Collins and C. S. Kortovich: Research on Microstructural Instability of Nicke1-Base Supera1loys. A. F. Contract 33 (615) 5126.

(3) R. W. Guard and J. H. Westbrook: The Alloying Behavior of NizAl (Gamma-Prime Phase). Met. Soc. AIME 215, 807 (1959).

(4) R. F. Decker and C. G. Bieber: Microstructure of a Cast Age Hardenable Nicke1-Chromium Alloy. Symposium on Electron Meta11ography, ASTM Special Technical Publication №. 262.

(5) M. P. Arbuzov, E. T. Kachkovskaya and B. V. Kaenko. Fisika Metallov i Metalovedenie, 1966, 21, (6), 854-857.

(6) W. J. Boesch and J. S. Slaney. Preventing Sigma Phase Embrittlement in Nicke1-Base Superalloys, Metal Progress, 86, 109, 1964.

(7) L. R. Woodyatt, C. T. Sims and H. J. Beattie, Jr. Prediction of Sigma-Type Phase Occurrence from Compositions in Austenitic Superalloys. Transactions, Met. Society AIME 236, 519 (1966).

(8) A. Taylor and R. W. Floyd. The constitution of Nickel-Rich Alloys of the Nicke1-Chromium-Aluminum System. Journal of the Institute of Metals, pp. 451-464, 81, 1952-53. 


\section{APPENDIX I}

\section{Assumptions and Constants for Variable} Gamma-Prime Prediction

\section{Carbides}

Assume

1. If $\mathrm{Mo}+\mathrm{W}$ a/o is Inore than $\mathrm{a} a / \mathrm{o}$, then $\mathrm{M}_{6} \mathrm{C}$ of composition $d$ is formed to reduce the Mo $+W$ a/o to a $a / o$.

2. If $\mathrm{Cb}+\mathrm{Ta}$ are present at more thain $\mathrm{b} a / o$, then all of the $\mathrm{C}$ forms $\mathrm{MC}$ of cormosition e.

3. If less than $\mathrm{b}$ a/o of $\mathrm{Cb}+\mathrm{Ta}$ are present, $\mathrm{c} \times \mathrm{C}$ a/o forms $M C$ of composition $f$ and $(1-c) \times C a / o$ forms $M_{23} C_{6}$ of composition $g$.

Borides

Assume

A11 of the $B$ forms $\mathrm{M}_{3} \mathrm{~B}_{2}$ of composition $\mathrm{a}^{\prime}$.

\section{Ganma-Prime}

Assume

1. $\mathrm{m}$ of $\mathrm{Al}, \mathrm{n}$ of $\mathrm{Ti}, \mathrm{O}$ of $\mathrm{Cb}$ and $\mathrm{p}$ of $\mathrm{Ta}$ enter gamma-prime on the Al side.

2. Composition of the gamma-prime is:

$$
\begin{aligned}
& \left(\mathrm{Ni}_{75-\Sigma \mathrm{NiS}}+\mathrm{Co}_{\mathrm{a} / \mathrm{oxh}}+\mathrm{Fe}_{\mathrm{a} / \mathrm{oxi}_{\frac{2}{2}}}+\mathrm{Cr}_{\mathrm{a} / \mathrm{oxj}_{\frac{2}{2}}}+\mathrm{Mo}_{\mathrm{a} / \mathrm{oxh}_{\frac{2}{2}}}+\mathrm{W}_{\mathrm{a} / \mathrm{oxl}_{\mathrm{Z}}}\right) \\
& (m A l+n T i+o C b+p T a)_{25-\Sigma A l_{S}}+\mathrm{Fe}_{a / o x \frac{1}{2}}+\mathrm{Cr}_{\mathrm{a} / \mathrm{oxj}_{\frac{2}{2}}}+\mathrm{Mo}_{\mathrm{a} / \mathrm{oxk}}+\mathrm{W}_{\mathrm{a}} \mathrm{ox}_{\frac{1}{2}}
\end{aligned}
$$


Appendix I

Page 2

Wherc

$\Sigma \mathrm{Ni}_{\mathrm{S}}=$ Sum of carbide and boride-adjusted atomic percentages of the nickel-substituting elements in the gamma-prime.

$\Sigma A I_{S}=$ Sum of carbide and boride adjusted atomic percentages of the aluminum-substituting elements in the gamma-prime.

and $a / o=$ Atomic percentage of the relevant element after the removal of carbides and borides from the matrices.

\section{Nv Calculation}

No changes are made here. The sum of the product of the residual atom

percentages and their appropriate multipliers, gives the final Nv number.

\section{Constants}

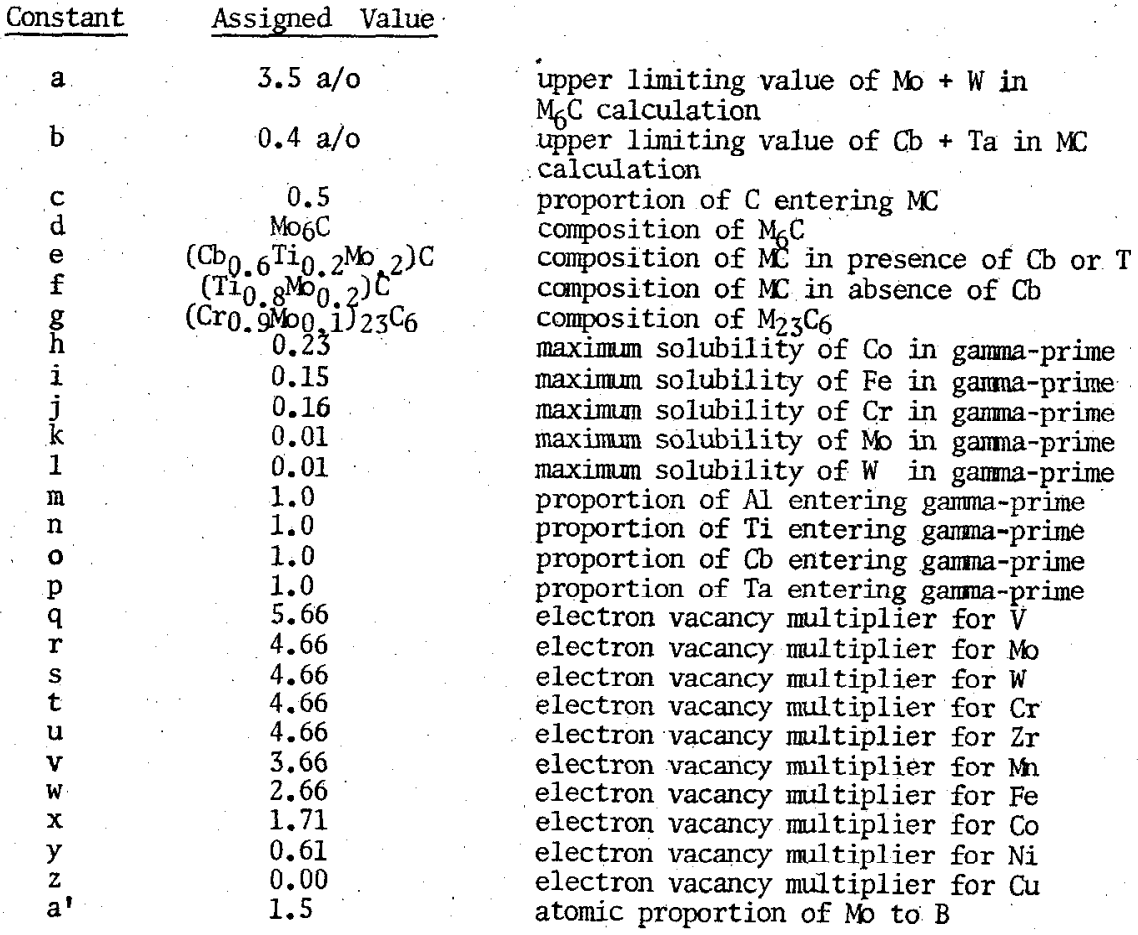


$\underline{A P P E N D I X I I}$

Sample Ca1culation of Variable

Precipitation Prediction Program for $713 \mathrm{C}$

\begin{tabular}{|c|c|c|c|c|c|c|c|}
\hline & $w / 0$ & At Wt. & w/o/at wt. & a/o & $\underline{C}^{\prime} \& B^{\prime} \operatorname{adj}$. & $y^{\prime}$ adj. & $a / 0$ \\
\hline C & 0.08 & 12.01 & .0066 & .36 & - & - & - \\
\hline Mo & 4.42 & 95.95 & .0462 & 2.54 & 2.393 & 2.369 & 6.30 \\
\hline W & - & 183.92 & - & - & - & - & - \\
\hline $\mathrm{Cb}$ & 2.66 & 92.91 & .0286 & 1.57 & 1.354 & - & - \\
\hline $\mathrm{Ta}$ & - & 180.88 & - & - & - & - & - \\
\hline $\mathrm{T} 1$ & 0.81 & 47.90 & .0169 & 0.93 & 0.858 & - & - \\
\hline $\mathrm{Cr}$ & 13.68 & 52.01 & .2630 & 14.45 & 14.45 & 13.294 & 35.30 \\
\hline Co & - & 58.94 & - & - & - & - & - \\
\hline $\mathrm{Fe}$ & - & 55.85 & - & - & - & - & - \\
\hline A1 & 6.20 & 26.97 & .2300 & 12.65 & 12.65 & - & - \\
\hline B & .009 & 10.82 & .0009 & .05 & .05 & - & - \\
\hline $\mathrm{Zr}$ & .06 & 91.22 & .0006 & .03 & .03 & .030 & .08 \\
\hline v & - & 50.95 & - & - & - & - & - \\
\hline $\mathrm{Ni}$ & 72.08 & 58.69 & $\frac{1.2300}{1.8228}$ & $\frac{67 \cdot 70}{100.28}$ & $\frac{67 \cdot 70}{99 \cdot 560}$ & $\frac{21.934}{37.627}$ & $\frac{58.30}{99.98}$ \\
\hline
\end{tabular}

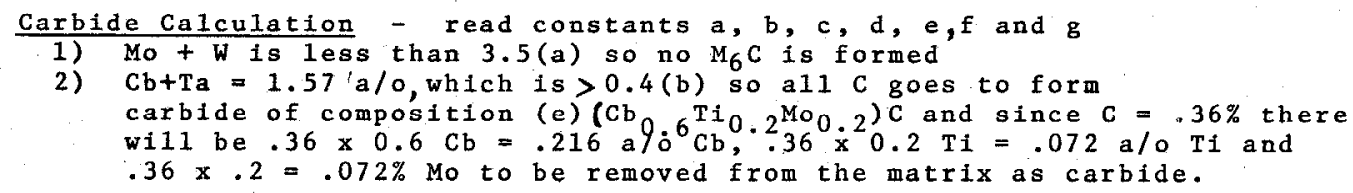

Boride Calculation - read constant $a^{\prime}$

Multiply B a/o by $1.5\left(\mathrm{a}^{\prime}\right)=.05 \times 1.5=.075 \mathrm{~B}$ to be removed as boride.

Gamma-Prime Calculation ( $\mathrm{Ni}_{75} \mathrm{Al}_{25}$ as base) read constant $\mathrm{h}, i, j$, Elements on $A l$ side of $\gamma^{\prime}, n, o$ and $P$.

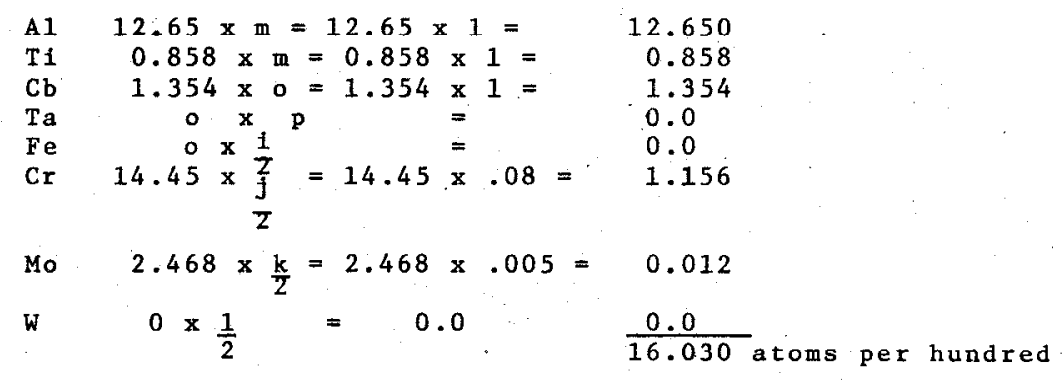


Appendix II

Page 2

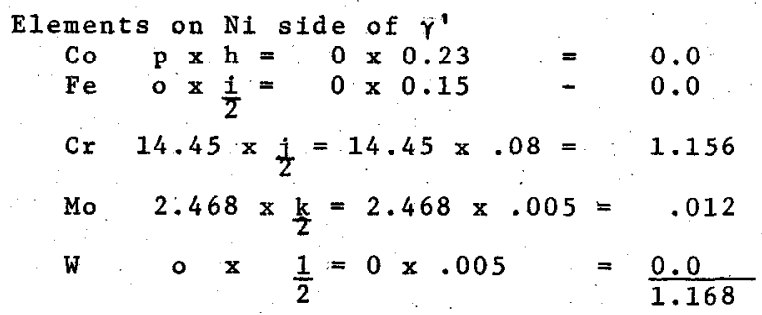

Carbide and Boride Adjustment

The remaining $c$ is therefore $.36-.36=0=0 \mathrm{a} / \mathrm{o} \mathrm{C}$
The remaining $\mathrm{Cb}$ is therefore $1.57-0.216=1.354 \mathrm{a} / \mathrm{Cb}$
The remaining $\mathrm{Ti}$ is therefore $0.93-0.072=0.858 \mathrm{a} / \mathrm{o} \mathrm{Ti}$
The remaining Mo is therefore $2.54-(0.072+0.075)=2.393 \mathrm{a} / \mathrm{o}$ Mo

Since the formula is $\mathrm{Ni} 3 \mathrm{Al}, 16.030$ atoms on the A1 side wi11 carry 16.030

x $3-48.090$ atoms on the Ni side. Now the non-Ni atoms on the Ni side = 1.168 ( $\mathrm{Cr}+\mathrm{Mo})$ so the Ni atoms wili be $48.090-1.168=46.922$ atoms.

So the $\gamma$ 'composition is. (in atoms)

$$
46.922 \quad \frac{\mathrm{NI}}{312} \quad \frac{\mathrm{Mo}}{.024} \quad 12 \frac{\mathrm{Al}}{650} \quad \frac{\mathrm{Ti}}{0.858} \quad \frac{\mathrm{Cb}}{1.354}
$$

and these amounts must be subtracted in the $\gamma^{\prime}$ adjustment.

Gamma-Prime Adiustment

Subtract $\gamma$ ' composition (in atoms) from the "C" and B' adj." column and enter in' " $\gamma$ " adjusted" column.

\section{Calculate New Matrix a/o}

By summing " $\gamma$ " adj." column and ratioing to $100 \%$.

Calculation of Ni Number

Read constants $q, r, s, t, u, v, w, x, y$, and $z$.

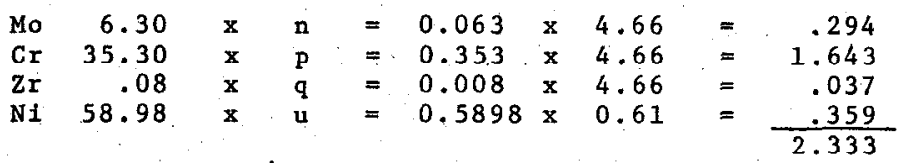




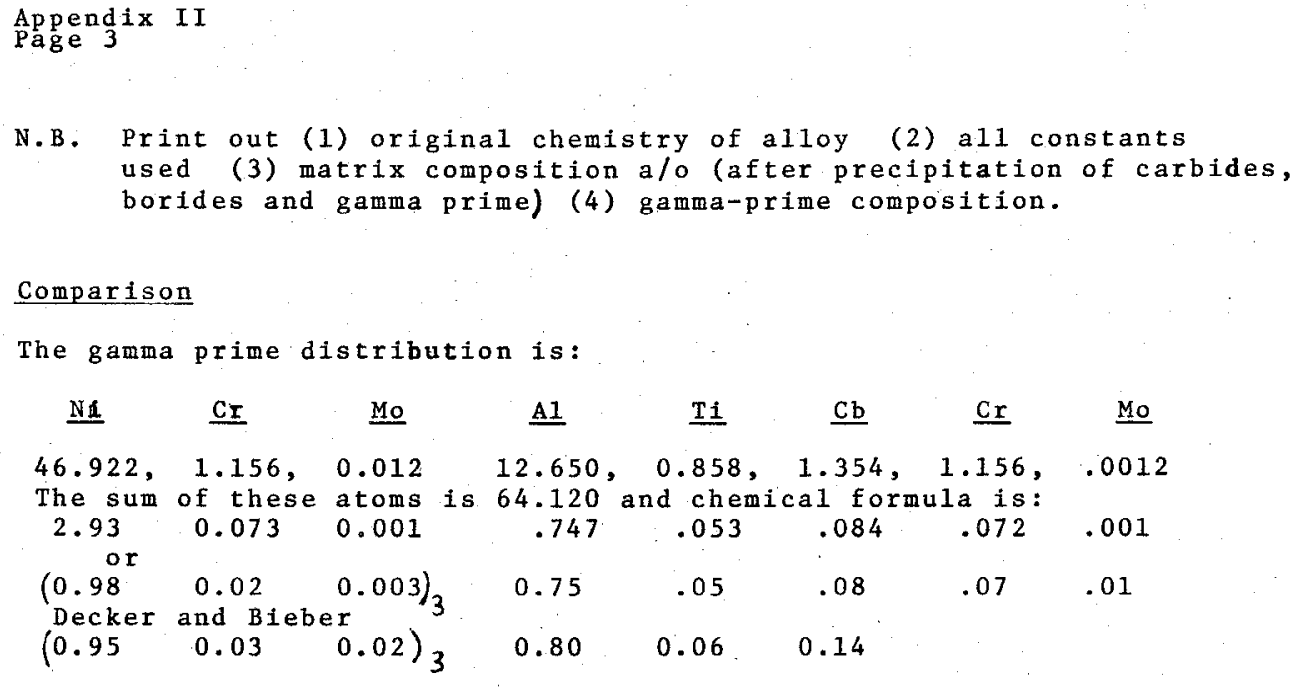

The gama primedistribution is:

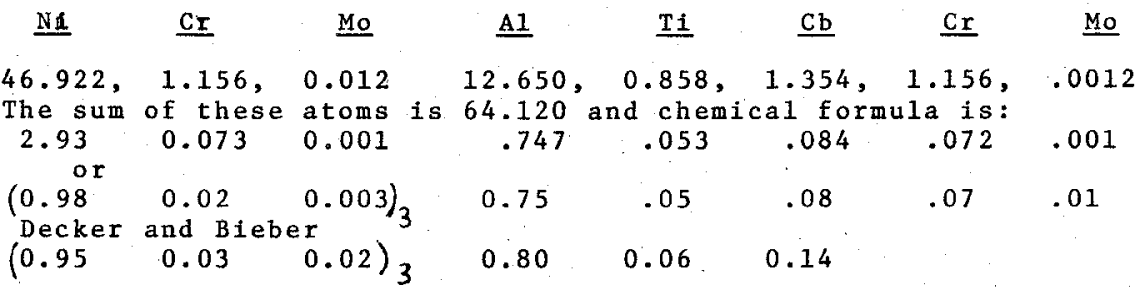


APPENDIX III

Calculation for Udimet 700

\begin{tabular}{|c|c|c|c|c|c|c|c|c|}
\hline & $w / 0$ & At Wt. & w/o/At Wt. & $a / 0$ & $\mathrm{C}^{\prime}$ adj. & $\mathrm{B}^{\prime} \mathrm{adj}$. & $\underline{y}^{\prime} \mathrm{adj}$ & $a / 0$ \\
\hline C & 0.06 & 12.01 & .0050 & 0.28 & - & - & - & \\
\hline Mo & 4.45 & 95.95 & .0464 & 2.56 & 2.479 & 2.269 & 2.247 & 5.25 \\
\hline $\mathrm{T} i$ & 3.45 & 47.90 & .0720 & 3.98 & 3.868 & 3.878 & - & \\
\hline $\mathrm{Cr}$ & 14.60 & 52.00 & .2810 & 15.45 & 14.966 & 14.966 & 12.574 & 29.45 \\
\hline Co & 17.60 & 58.94 & .2970 & 16.45 & & 16.450 & 12.660 & 29.65 \\
\hline A1 & 4.37 & 26.97 & .1617 & 8.93 & & 8.930 & - & \\
\hline B & .028 & 10.82 & .0026 & 0.14 & & - & & \\
\hline $\mathrm{Fe}$ & $\frac{0.14}{44.70}$ & 55.85 & .0025 & 0.14 & & 0.140 & 0.110 & 0.26 \\
\hline $\mathrm{Ni}$ & 55.30 & 58.69 & $\frac{.9420}{1.8110}$ & $\frac{52.20}{100.13}$ & & 52.200 & $\frac{15.152}{42.743}$ & $\frac{35.05}{99.66}$ \\
\hline
\end{tabular}

Carbide

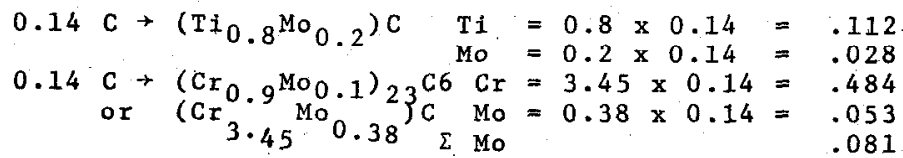

Bor1de

$0.14 \mathrm{~B}+\mathrm{Mo}_{3} \mathrm{~B}_{2} \quad$ Mo $=1.5 \times 0.14 \quad .21$

Gamma-Prime

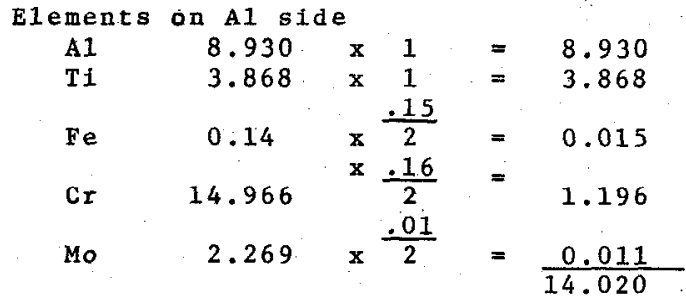


Appendix II I

Page 2

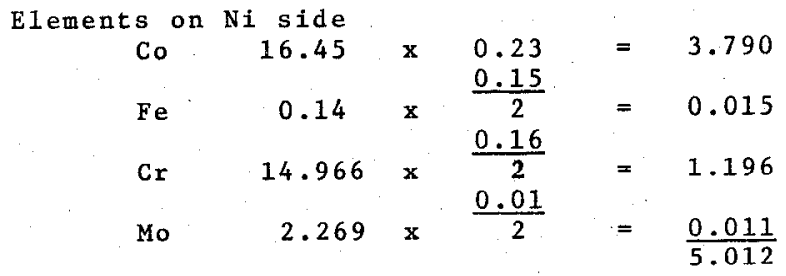

$14.020 \Delta 1$-side atoms carry $14.020 \times 3 \mathrm{Ni}$-side atoms $=42.060$

but $\frac{5.012}{37.048}$ are Ni substitutes

so $\overline{37.048}$ are $\mathrm{Ni}$ atoms

$N_{\text {Valculation }}$

\begin{tabular}{llllll} 
Mo & .0525 & $\mathbf{x}$ & 4.66 & $=$ & 0.244 \\
$\mathrm{Cr}$ & .2945 & $\mathbf{x}$ & 4.66 & $=$ & 1.371 \\
$\mathrm{Fe}$ & .0026 & $\mathbf{x}$ & 2.66 & $=$ & .007 \\
$\mathrm{Co}$ & .2965 & $\mathbf{x}$ & 1.71 & $=$ & .496 \\
$\mathrm{Ni}$ & .3505 & $\mathrm{x}$ & 0.61 & $=$ & .214 \\
\hline
\end{tabular}

Gamma-Prime Prediction

\begin{tabular}{|c|c|c|c|c|c|c|c|c|c|}
\hline$\underline{\mathrm{N1}}$ & Co & $\underline{\mathrm{Fe}}$ & $\underline{\mathrm{Cr}}$. & Mo & $\underline{\mathrm{A} 1}$ & $\underline{T i}$ & $\underline{\text { Fe }}$ & $\underline{\mathrm{Cr}}$ & $\underline{\text { Mo }}$ \\
\hline 37.05 & 3.79 & 0.01 & 1. 20 & 0.01 & 8.93 & 3.87 & 0.01 & 1.20 & 0.01 \\
\hline $\begin{array}{l}\text { Sum of } \\
2.64 \\
\text { and the }\end{array}$ & $\begin{array}{l}\text { atoms } \\
0.27 \\
\text { chemi }\end{array}$ & $\begin{array}{l}=42.060 \\
\text { neg. } \\
=\text { a1 forn }\end{array}$ & $\begin{array}{r}+14 \\
0.09 \\
\text { ula wo }\end{array}$ & $\begin{array}{l}20= \\
\text { neg. } \\
\text { ald be }\end{array}$ & $\begin{array}{l}.08 \\
0.64\end{array}$ & $\begin{array}{l}\mathrm{ms} \\
0.28\end{array}$ & neg. & 0.09 & neg. \\
\hline
\end{tabular}

